\title{
Pre-Adipocyte Determination and Adipocyte Differentiation of Stromal Vascular Cells Isolated From Intramuscular Tissue of Hanwoo Beef Cattle Treated by Acetate and Propionate
}

\author{
T. G. Wandita ${ }^{a}$, N. Joshi ${ }^{a}$, H. H. Kim ${ }^{\mathrm{b}}$, S. J. Anc, \& S. G. Hwanga,* \\ ${ }^{a}$ Department of Animal Life and Environmental Science, Hankyong National University \\ 327 Jungang-ro, Anseong-si, Gyeongi-do, 456-749, South Korea \\ ${ }^{b}$ Department of Food Science and Technology, Shin Ansan University \\ 135 Shin Ansan Daehak-ro, Ansan-si, Gyeonggi-do, South Korea 15435 \\ 'Hoengseong County, Gangwon-do, South Korea \\ *Email of corresponding author: sghwang@hknu.ac.kr \\ (Received 12-07-2018; Reviewed 03-09-2018; Accepted 28-09-2018)
}

\begin{abstract}
The effects of acetate and propionate in enhancing intramuscular fat (marbling) deposition in beef cattle are poorly understood. This study aimed to evaluate the effects of acetate and propionate on preadipocyte determination and adipocyte differentiation in stromal vascular cells (SVC) isolated from the intramuscular tissue of Hanwoo beef cattle. SVC were isolated and treated with different concentrations of acetate and propionate $(0.125$ to $1 \mathrm{mM})$. Pre-adipocyte determination was observed through the Zfp423 (Zinc finger protein 423) and Pref-1 (Pre-adipocyte factor-1) genes expressions, which were important transcription factors used to identify committed pre-adipocytes. Adipocyte differentiation was determined based on the lipid accumulation, triglyceride contents, and their molecular activities related to adipogenic markers. The results suggest that acetate supports pre-adipocyte determination in SVC which is observed to increase the expression of Zfp423 and Pref-1 along with the increasing acetate concentration. Propionate treatment was seen to significantly affect lipid accumulation as well as triglyceride content in SVC, compared to acetate treatment. Furthermore, propionate treatment very significantly increased the expressions of PPAR $\gamma$, C/EBP $\alpha$, SREBP-1c, and FABP4. In conclusion, acetate likely enhances pre-adipocyte determination, while propionate effectively promotes adipogenesis in SVC isolated from the intramuscular tissue of Hanwoo beef cattle.
\end{abstract}

Keywords: acetate, adipogenesis, Hanwoo, marbling, propionate

\section{INTRODUCTION}

Consumers prefer beef that is tender and juicy, characteristics that are seen very important to its palatability. Development of marbling adipose tissue is essential for increasing the tenderness in beef, while connective tissue or subcutaneous fat contributes to its toughness. Marbling is the visible intramuscular fat within a cross-section of meat, and is positively correlated with beef juiciness, perceived tenderness, and palatability (Wheeler et al., 1994; Albrecht et al., 2011). The intramuscular fat depositions of native Korean Hanwoo beef cattle increase by more than $30 \%$, over the course of more than two decades (Smith \& Johnson, 2016).

The formation and growth of adipose tissue involve both hyperplasia (increased cell numbers) and hypertrophy (increased cell size). Adipogenesis is the process of proliferation of pre-adipocytes and their differentiations into mature adipocytes. Pre-adipocytes and adipocytes are major factors for adipose tissue expansion, as well as being the main contributors to intramuscular fat deposition. Hypertrophy of adipocytes occurs as they accumulate triglycerides created through lipogenesis (Hausmann et al., 2001; Fernyhough et al., 2007; Brooks et al., 2011; Lee et al., 2010). Because of the importance of adipogenesis, many scientists are carrying out research to enhance intramuscular fat deposition by different approaches.

Zfp423 (Zinc finger protein 423), which is abundantly found in pre-adipose adipoblasts, has been identified as a critical regulator of the pre-adipocyte determination in the primary cell cultures (Gupta et al., 2010; Huang et al., 2012; Moseti et al., 2016). The Zfp423 expression is augmented in numerous pre-adipocyte cell lines when compared to numerous fibroblast cell lines (Visvanath et al., 2016). Zfp423 regulates pre-adipocyte levels of PPAR $\gamma$, and is required for proper differentiations of white and brown adipocytes in vitro and in vivo (Shao et al., 2016; Moseti et al., 2016). In addition, the other regulators of the PPAR $\gamma$ expression, such as $\mathrm{C} / \mathrm{EBP} \alpha$, may be expressed to compensate for the loss of Zfp423, in order to maintain the expressions of adipocyte transcription factor. By contrast, in mature white adipocytes, Zfp423 is able to suppress the thermo-genic 
gene program associated with beige/brown adipocytes. It regulates the initial formation of white adipocytes and later plays a role in maintaining energy storage.

Volatile fatty acids (VFAs), a primary source of energy for ruminants, are produced from microbial fermentation of feed carbohydrates in the rumen (Wattiaux, 1996; Hong et al., 2005). Acetate is the most common VFA produced in the rumen, and high levels of acetate maintain a stable fermentation in the rumen, and stabilize its $\mathrm{pH}$. Excess acetate increases propionate production, decreases rumen $\mathrm{pH}$, reduces feed intake, and reduces microbial reproduction (Russell, 1998; Aschenbach et al., 2009). High levels of propionate in the rumen might, in turn, lead to the depressed fiber digestion and acidosis. Moreover, glucose contributes a greater proportion of the carbon used for fatty acid biosynthesis in intramuscular sites, rather than in subcutaneous adipose tissue, while acetate is thought to contribute to the development of committed pre-adipocytes (Hausman et al., 2009; Nayananjalie et al., 2015).

Because acetate and propionate are the most common VFAs, their roles in cattle metabolism become an interesting issue in relation to intramuscular fat deposition in adipose tissue. Either acetate or propionate is thought to be required by the mesenchymal stem cells to develop into pre-adipocytes and adipocytes, although the precise understanding of the function and performance of acetate and propionate in the adipose tissue of beef cattle is still lacking. Therefore, this study aimed to investigate and clarify the effect of different levels of acetate and propionate on the proliferation and differentiation of stromal vascular cells (SVC) isolated from bovine intramuscular fat.

\section{MATERIALS AND METHODS}

\section{Stromal Vascular Cell Isolation}

According to dela Cruz et al. (2015), SVC adipose tissue was isolated from the muscle tissue (Longissimus dorsi) of three different samples of 15-month old castrated Hanwoo beef cattle. The muscles were collected directly from a slaughterhouse in Anseong (Gyeonggi Province, South Korea). During transportation to the laboratory, the samples were placed in a sterile ice-cold Phosphate Buffer Saline (PBS, Gibco \#1957829), which contained Amphotericin B at a concentration of $1 \mathrm{ml} / \mathrm{L}$ (Sigma Aldrich, \#2942) and gentamycin at a concentration of $4 \mathrm{ml} / \mathrm{L}$ (Sigma Aldrich, \#G1397). Adipose tissue was then resected and put in an isolation media $(10 \%$ Bovine Calf Serum (BCS, Gibco \#1749272) in 1 L of Dulbecco's Modified Eagle's Medium (DMEM, Gibco \#1927561) containing collagenase type 1 at a concentration of $1 \mathrm{mg} / \mathrm{mL}$ (Sigma Aldrich, \#C2130) and bovine serum albumin at a concentration of $0.4 \mathrm{~g} / \mathrm{mL}$ (Sigma Aldrich, \#A4503).

Digestion was performed for $50 \mathrm{~min}$, at $37^{\circ} \mathrm{C}$, in an agitated water bath, operating at a speed of 60 cycles per min. After digestion, $5 \mathrm{~mL}$ of BCS-DMEM was added to the isolating media to stop the digestion, and the suspension was filtered using a nylon cell strainer with a pore size of $100 \mu \mathrm{m}$, and was then centrifuged at 1000 rpm for $10 \mathrm{~min}$, at room temperature. The filtrate was then washed in $10 \mathrm{ml}$ of RBC Lysis (Sigma Aldrich, \#R7757) and centrifuged for $1000 \mathrm{rpm}$ for $10 \mathrm{~min}$, at room temperature. The cells were then re-suspended in $10 \mathrm{~mL}$ of growing media (10\% BCS-DMEM containing $1 \%$ penicillin-streptomycin (Lonza, \#17-602E)). The cells were incubated at $37^{\circ} \mathrm{C}$ under $5 \% \mathrm{CO}_{2}$ until fully attached to the plate. Every 2 days after isolation, the growing media was renewed, to maintain cell cultures.

\section{Stromal Vascular Cell Culture and Treatments}

The cells were cultured in 10\% Fetal Bovine Serum (FBS, Biowest \#S1520)-DMEM supplemented with $1 \%$ Penicillin-streptomycin as the cells commenced to differentiate. In order to accelerate cell differentiation, on the day of differentiation, the cells were induced with $10 \mu \mathrm{L}$ each of $0.5 \mathrm{mM}$ isobuthylmethylxanthine (IBMX, Sigma Aldrich \#I5879), $1 \mu \mathrm{M}$ dexamethasone (DEX, Sigma Aldrich \#D4902), insulin at a concentration of $10 \mu \mathrm{g} / \mathrm{mL}$ (INS, Sigma Aldrich \#I6634), and rosiglitazone (Sigma Aldrich, \#R2408). Every 2 days, the media was replaced with a fresh FBS-DMEM, and induced with only insulin and rosiglitazone (dela Cruz et al., 2015).

As the SVC proliferated and continued differentiation, they were treated with different concentrations of 98.5\% sodium acetate trihydrate (Samchun Chemicals, \#S0274) and 99.0\% sodium propionate (Sigma Aldrich, \#P5436) $(0.125,0.25,0.5$, and $1 \mathrm{mM})$. These experiments were repeated 3 times.

\section{Cells Viability Assay}

To determine the effects of different concentrations of acetate and propionate on SVC adipose tissue, Cell Counting Kit-8 assays (Dojindo, \#CK04) were performed at the $72 \mathrm{~h}$ point. The cells were seeded in a 96-well plate, and treated with different concentrations of acetate and propionate; the cells were then incubated for $72 \mathrm{~h}$, and then CCK-8 reagent was added to the cells, and the mixture was allowed to stand for $2 \mathrm{~h}$. Optical density was then measured at $450 \mathrm{~nm}$ in a micro plate reader, with the estimated number of treated cells shown as the percentage of control cells (dela Cruz et al., 2015).

\section{Pre-adipocyte Proliferation}

Based on the manufacturer's protocol, the cells were seeded in 6-well plates, at a density of $1 \times 10^{8}$ cells/ well, and treated with different concentrations of acetate and propionate. The cells were incubated, and then harvested at $72 \mathrm{~h}$. Total RNA was extracted from each plate using RNAiso Plus (Takara Shuzo Co., \#TR118), and then cDNA was synthesized from the RNA sample using a ThermoFisher Co. PCR set, containing $10 \mathrm{mM}$ dNTP Mix (\#R0191), $0.2 \mu \mathrm{g} / \mu \mathrm{L}$ random hexamer primer (\#S014), $40 \mathrm{U} / \mu \mathrm{L}$ RiboLockRNAse inhibitor (\#E00381), 200 U/ $\mu \mathrm{L}$ RevertAid Reverse Transcriptase, and 5× reaction buffer. Reverse-Transcriptase Polymerase Chain Reaction was performed to identify the expression of Zfp423 and Pref-1. The following oligonucleotide prim- 
ers were used in PCR: $\beta$-actin forward: 5'-CGC CAT GGA TGA TGA TAT TGC-3'; $\beta$-actin reverse: $5^{\prime}$-AAG CGG CCT TGC ACA T-3'; Zfp423 forward: 5'-GGA TTC CTC CGT GAC AGC A-3'; Zfp423 reverse: 5' - TCG TCC TCA TTC CTC TCC TCT-3'; Pref-1 forward: 5'-CTC CCA GGC CAT CTG CTT C-3'; and Pref-1 reverse: 5'ACA TGT GGT TGT AGC GCA GA-3'.

\section{Oil Red O Staining}

The amount of lipid accumulation from fully differentiated SVC was determined with Oil Red O staining on day 14. Differentiated cells were fixed with $10 \%$ formaldehyde in a PBS for $1 \mathrm{~h}$ at $37^{\circ} \mathrm{C}$, and then washed with distilled water. The plate was then inverted and blotted against clean paper towels. To equilibrate the differentiated cells before staining, 60\% isopropanol was added to each well, which were then washed with distilled water, and dried. The cells were stained with $2 \mathrm{~mL} /$ well of Oil Red O solution (300 mg of Oil Red O powder (Sigma Aldrich, \#O0625) diluted in $100 \mathrm{ml}$ of $99 \%$ isopropanol (Sigma Aldrich, \#19516)) for $2 \mathrm{~h}$ at room temperature, then washed with distilled water. The plate was then inverted and blotted against clean paper towels until the bottom plate was dried. Differentiation was observed under the microscope. Triglyceride analysis was quantified by elution with isopropanol, and the optical density was measured at $490 \mathrm{~nm}$.

\section{Reverse-Transcriptase Polymerase Chain Reaction}

Based on the manufacturer's protocol, fully differentiated SVC were harvested using RNAiso Plus (Takara Shuzo Co., \#TR118), and then cDNA was synthesized from the RNA sample using a ThermoFisher Co. PCR set, containing $10 \mathrm{mM}$ dNTP Mix (\#R0191), $0.2 \mu \mathrm{g} / \mu \mathrm{L}$ random hexamer primer (\#S014), $40 \mathrm{U} /$ $\mu \mathrm{L}$ RiboLockRNAse inhibitor (\#E00381), $200 \mathrm{U} / \mu \mathrm{L}$ RevertAid Reverse Transcriptase, and $5 \times$ reaction buffer. A maxime RT Premix Kit (iNtRON Biotechology, \#25026) was used to mix $1 \mu \mathrm{g}$ of cDNA and $20 \mu \mathrm{L}$ of primer marker. The cDNA was then incubated in a thermocycler for an initial denaturation cycle, at $95^{\circ} \mathrm{C}$ for 5 min, followed by 30 amplification cycles of $40 \mathrm{~s}$ at $95^{\circ} \mathrm{C}$,

Table 1. List of primers used in the PCR analysis to identify the effect of acetate and propionate on differentiated stromal vascular cells (SVC) isolated from adipose tissue

\begin{tabular}{cll}
\hline \multirow{2}{*}{ Genes } & \multicolumn{1}{c}{ Primers } \\
\cline { 2 - 3 } & \multicolumn{1}{c}{ Forward } & \multicolumn{1}{c}{ Reverse } \\
\hline$\beta$-actin & 5'-CGC CAT GGA TGA & 5'-AAG CGG CCT TGC \\
& TAT TGC-3' & ACA T-3' \\
PPAR $\gamma$ & 5'-CAT CTT CCA GGG & 5'-GGA TAT GAG GAC \\
& GTG TCA GT-3' & CCA TCC T-3' \\
C/EBP $\alpha$ & 5'-GCT GAC CAG TGA & 5'-CTT GAC CAG GGA \\
& CAA TGA CC-3' & GCT CTC G-3' \\
FABP4 & 5'-AAG CTG CAC TTC & 5'-GAC CAC ACC CCC \\
& TTT CTC ACC-3' & ATT CAA AC-3' \\
SREBP-1c & 5'-ACC GCT CTT CCA & 5'-TTC AGC GAT TTG CTT \\
& TCA ATG AC-3' & TTG TG-3' \\
\hline
\end{tabular}

annealing for $40 \mathrm{~s}$ at $50-60^{\circ} \mathrm{C}$, and final extension at $72^{\circ} \mathrm{C}$ for 1 min (dela Cruz et al., 2015). The oligonucleotide primers used in this study were shown in Table 1.

\section{Western Blotting}

Protein was extracted from fully differentiated SVC by adding $200 \mu \mathrm{L}$ of protein extraction solution (iNtRON Biotechnology, \#17081). The lysates were purified by centrifugation at $15000 \mathrm{rpm}$ for $14 \mathrm{~min}$ at $4^{\circ} \mathrm{C}$, and protein concentrations were then determined using Bradford assay. To prepare the electrophoresis gel, $35 \mu \mathrm{g}$ of the protein sample was separated by vertical electrophoresis (SDS-PAGE), and transferred to nitrocellulose transfer membranes. The membranes were blocked with 5\% skimmed milk, and hybridized with the following primary $\mathrm{Abcam}^{\mathrm{TM}}$ antibodies: mouse monoclonal anti-beta actin (ab6276), rabbit polyclonal anti-PPAR gamma (ab45036), rabbit polyclonal anti-FABP4 (ab85875), rabbit polyclonal anti-CEBP alpha (ab140479), and mouse monoclonal anti-SREBP1 from Santa Cruz Biotechnology (sc-365513). The target protein was exposed and detected on radiographic film, after membrane incubation with horseradish peroxidase (HRP, AB Frontier \#LF-QC0103), to enhance the chemiluminescence.

\section{Statistical Analysis}

All the quantitative data were shown as the mean \pm SD. Differences between groups were analyzed using one-way ANOVA, followed by Duncan's Multiple Range Test (DMRT). The level of statistical significance was set at $\mathrm{P}<0.05$. The statistical software package SPSS 15.0 (SPSS Inc., Chicago, Ill., USA) was used for the analysis.

\section{RESULTS}

Cell viability was determined to evaluate the effects of acetate and propionate in different concentrations $(0.125,0.25,0.5$, and $1.0 \mathrm{mM})$ on proliferating SVC isolated from Hanwoo beef cattle at 72 h. CCK-8 assay was conducted in order to evaluate the viability of the SVC. The results showed that acetate and propionate promoted SVC proliferation, as were presented in Figure 1. Cell viability initially increased, for both tests, along with the increases in the concentrations of acetate and propionate, up until reaching the concentration of $1.0 \mathrm{mM}$, at which point maximum cell viability was reached. Neither acetate nor propionate had cytotoxic effects on the SVC, and the results suggested that different levels of acetate and propionate affected cells proliferation.

To identify the existence of pre-adipocytes, gene expressions for Zfp423 and Pref-1, transcription factors that become critical regulators for determining committed pre-adipocytes, were performed. As shown in Figure 2A, representative mRNA bands for Zfp423 and Pref- 1 were significantly expressed after treatment for $72 \mathrm{~h}$ with different concentrations of acetate. The result suggested that acetate promoted pre-adipocyte determination in SVC isolated from Hanwoo beef 
cattle. Interestingly, representative mRNA bands for Zfp423 and Pref-1 were not significantly expressed in the propionate-treated group, which showed a similar expression for all concentrations; in other words, this study has shown that committed pre-adipocyte determination in bovine SVC was not affected by the increasing concentration of propionate. The result suggested that propionate did not promote pre-adipocyte determination in SVC isolated from Hanwoo beef cattle.

Oil red $\mathrm{O}$ staining and triglyceride content analysis were performed to evaluate the effect of different levels of acetate on the adipogenic differentiation of SVC. Figure $3 \mathrm{~A}$ shows that the increasing concentration of acetate until $1.0 \mathrm{mM}$ significantly increased cytoplasmic lipid accumulation, shown by the increased number of areas developed as red spots. Negative control and positive control were provided to differentiate the MDI treatment. These data suggested that the increasing level of acetate up to $1.0 \mathrm{mM}$ stimulated the mesenchymal stem cells to differentiate into adipocytes, and increased the accumulation of lipid. In this study, the highest lipid accumulation was shown by the addition of $1.0 \mathrm{mM}$ acetate, as was shown by the increased number of red stained fat droplets in Figure 3B.

Unlike the acetate effects, propionate showed an excellent result for the lipid accumulation. As was

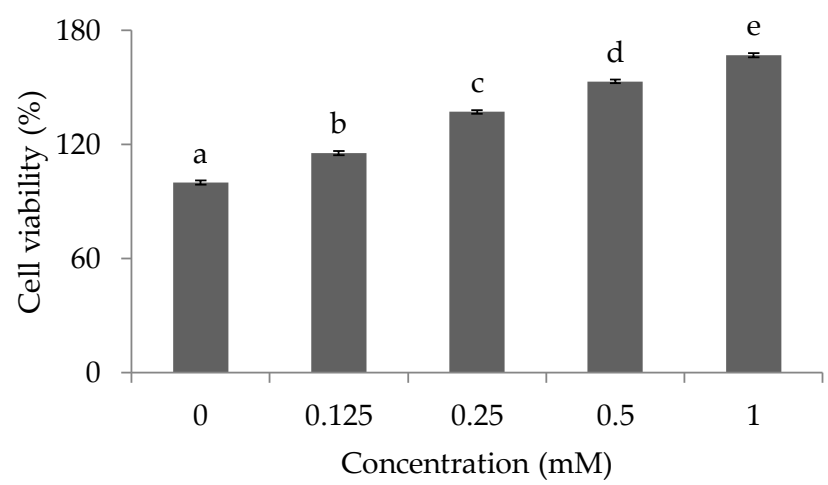

(A)

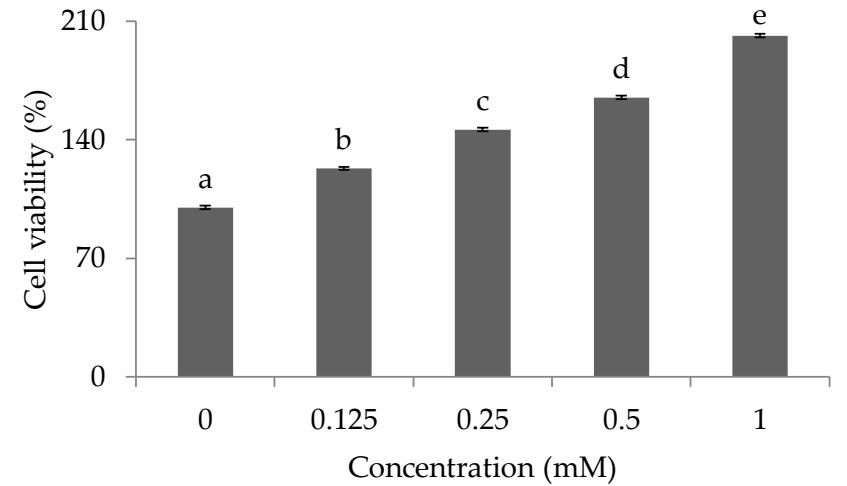

(B)

Figure 1. Stromal vascular cells (SVC) proliferation after $72 \mathrm{~h}$ treatments treated with different concentrations of (A) acetate and (B) propionate. Data are means \pm SD of four replicate experiments. Bars with different superscripts are significantly different $(\mathrm{P}<0.05)$.

(A)

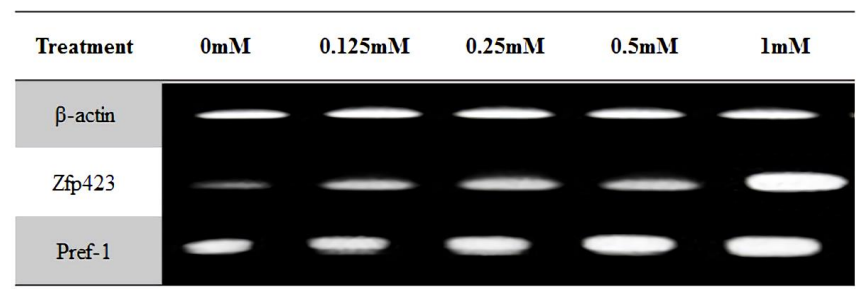

(B)

\begin{tabular}{lllllll}
\hline Treatment & $0 \mathrm{mM}$ & $0.125 \mathrm{mM}$ & $0.25 \mathrm{mM}$ & $0.5 \mathrm{mM}$ & $1 \mathrm{mM}$ \\
\hline$\beta$-actin & & & & & \\
$\mathrm{Zfp} 423$ & & & & & & \\
Pref-1 & - & - & & & & \\
\hline
\end{tabular}

Figure 2. Representative mRNA bands of committed pre-adipocytes genes expressions, Zfp423 and Pref-1, in stromal vascular cells (SVC) isolated from Hanwoo beef cattle after $72 \mathrm{~h}$ treatments with different concentrations of (A) acetate and (B) propionate.

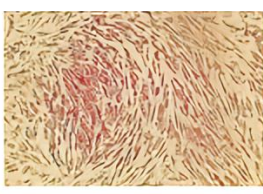

$\mathrm{NC}$

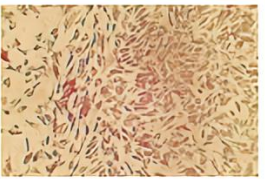

$0.25 \mathrm{mM}$

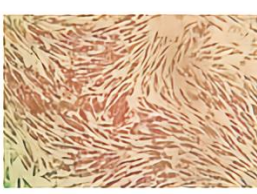

PC

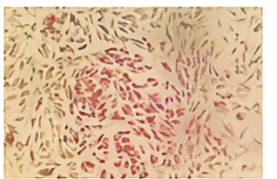

$0.5 \mathrm{mM}$

(A)

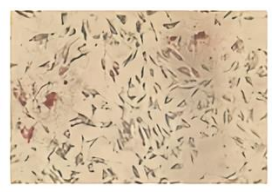

$0.125 \mathrm{mM}$

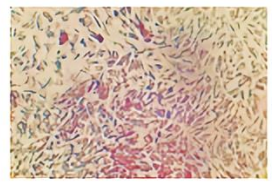

$1 \mathrm{mM}$

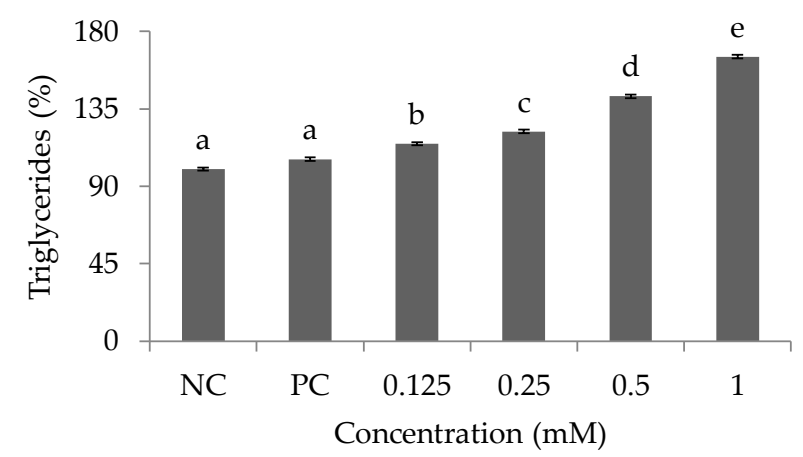

(B)

Figure 3. Stromal vascular cells (SVC) differentiation after 14 days treated with different levels of acetate. (A) Representative microscopic morphological images of lipid accumulation in SVC stained with Oil-Red-O. (B) The Oil-Red-O was washed with isopropanol and measured at $520 \mathrm{~nm}$. Data are means \pm SD of five replicate experiments. Bars with different superscripts are significantly different $(\mathrm{P}<0.05)$. 
shown in Figure 4A, the areas of red spots increased and the differentiation was perfectly developed. Figure 4B showed that the accumulated lipid in bovine SVC, after treatment with different concentrations of propionate, also increased, along with the increased concentration of propionate.

Pre-adipocyte differentiation into mature adipocytes can also be identified from their molecular activities, such as the gene and protein expressions. In this study, further experiments were conducted to evaluate several expressions of adipogenic-related markers, such as PPAR $\gamma, \mathrm{C} / \mathrm{EBP} \alpha$, SREBP-1c, and $\mathrm{FABP} 4$, in both genes and proteins, through Reverse
Transcriptase-Polymerase Chain Reaction and Western blot experiments.

As was shown in Figure 5, genes and protein expressions of differentiated SVC treated with different concentrations of acetate showed to support lipid accumulation results. All adipogenic transcription factors for genes and protein expression showed that increasing the concentration of acetate up to $1.0 \mathrm{mM}$ also increased the PPAR $\gamma, \mathrm{C} / \mathrm{EBP} \alpha$, SREBP-1c, and FABP4 expressions; at higher concentrations, they decreased. This suggested that concentration of acetate up to a maximum of 1.0 $\mathrm{mM}$ was effective for the differentiation of bovine SVC.

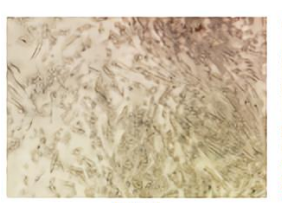

$\mathrm{NC}$

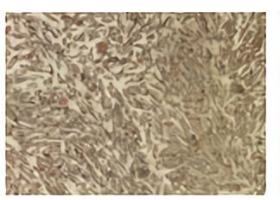

$0.25 \mathrm{mM}$

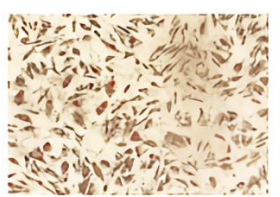

PC

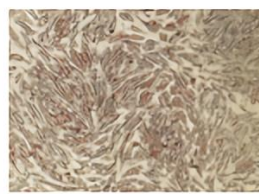

$0.5 \mathrm{mM}$

(A)

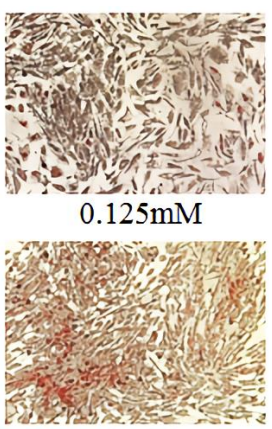

$1 \mathrm{mM}$

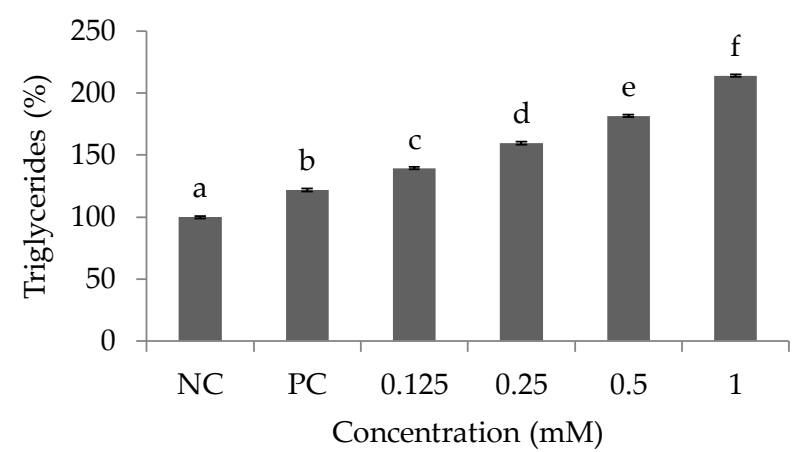

(B)

Figure 4. Stromal vascular cells (SVC) differentiation after 14 days treated with different levels of propionate. (A) Representative microscopic morphological images of lipid accumulation in SVC stained with Oil-Red-O. (B) The Oil-Red-O was washed with isopropanol and measured at $520 \mathrm{~nm}$. Data are means \pm SD of six replicate experiments. Bars with different superscripts are significantly different $(\mathrm{P}<0.05)$.

(A)

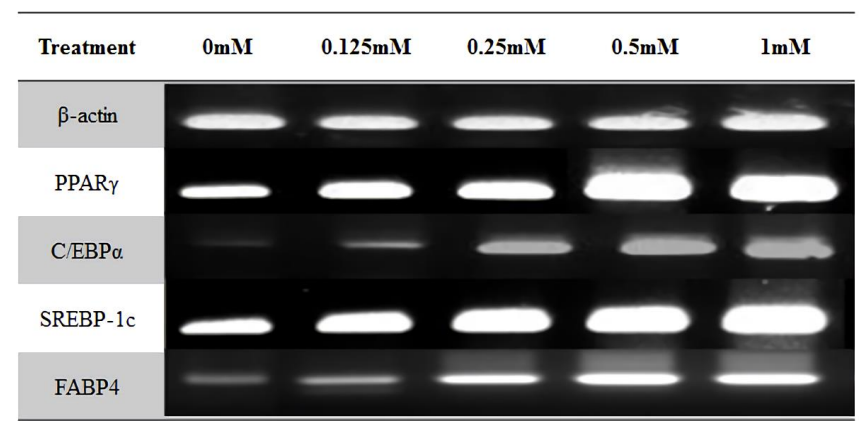

(B)

\begin{tabular}{|c|c|c|c|c|c|}
\hline Treatment & $0 \mathrm{mM}$ & $0.125 \mathrm{mM}$ & $0.25 \mathrm{mM}$ & $0.5 \mathrm{mM}$ & $\operatorname{lm} M$ \\
\hline$\beta$-actin & & $\longrightarrow$ & $\longrightarrow$ & & \\
\hline $\operatorname{PPAR} \gamma$ & & & 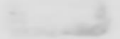 & & \\
\hline $\mathrm{C} / \mathrm{EBP} \alpha$. & - & - & & & \\
\hline SREBP-1c & & now & & & \\
\hline FABP4 & $x^{2}$ & heoner & thas & rases & \\
\hline
\end{tabular}

Figure 5. Representatives of (A) mRNA bands and (B) protein bands related with adipogenesis of fully differentiated stromal vascular cells (SVC) after treatment with different levels of acetate.

(A)

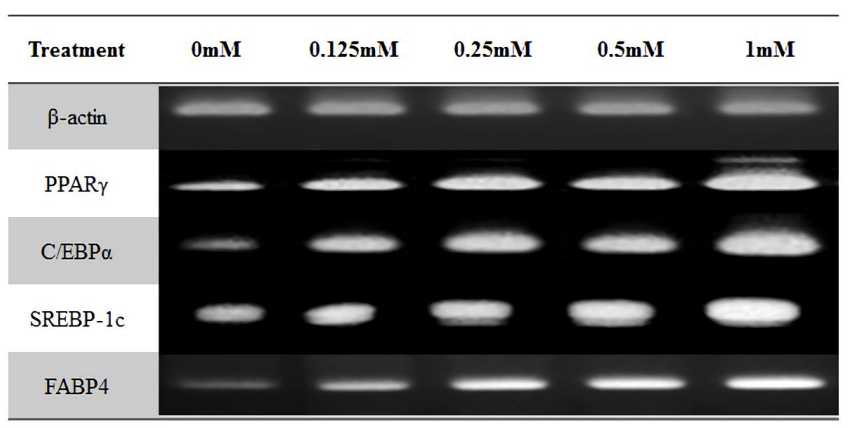

(B)

\begin{tabular}{|c|c|c|c|c|c|}
\hline Treatment & $0 \mathrm{mM}$ & $0.125 \mathrm{mM}$ & $0.25 \mathrm{mM}$ & $0.5 \mathrm{mM}$ & $\operatorname{lmM}$ \\
\hline \multicolumn{6}{|l|}{$\beta$-actin } \\
\hline $\operatorname{PPAR} \gamma$ & 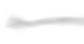 & 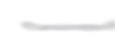 & 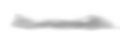 & A & 4 \\
\hline \multicolumn{6}{|l|}{$\mathrm{C} / \mathrm{EBP} \alpha$} \\
\hline SREBP-1c & & $\mathrm{at}=\mathrm{k}$ & $=$ & 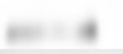 & 10 \\
\hline FABP4 & & & - & - & 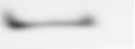 \\
\hline
\end{tabular}

Figure 6. Representatives of (A) mRNA bands and (B) protein bands related with adipogenesis of fully differentiated stromal vascular cells (SVC) after treatment with different levels of propionate. 
As was shown in Figure 6, as expected, genes and protein expressions of differentiated SVC treated with different concentrations of propionate showed to support lipid accumulation results. All adipogenic transcription factors for genes and protein expressions showed that increasing the concentration of propionate up to $1.0 \mathrm{mM}$ also increased the expressions of PPAR $\gamma$, C/EBP $\alpha$, SREBP-1c, and FABP4. The results suggested that both genes and protein expressions were significantly influenced by different concentrations of propionate, illustrating a very well significant effect of propionate on bovine SVC, compared with acetate.

\section{DISCUSSION}

Adipogenesis is an inclusive term describing the proliferation, differentiation, and expansion of cells into lipid-assimilating cells which are found in fat tissue (Fernyhough et al., 2007). One method to determine the mechanism of adipogenesis in cattle is by using primary cell cultures isolated from adipose tissue. Primary SVC cultures contain multiform cell populations that include pre-adipocyte progenitors and mesenchymal stem cells (Kraset al., 1999). Mesenchymal stem cells stimulated with certain signaling pathways could be committed into adipocytes. On the way to becoming adipocytes, mesenchymal stem cells will firstly develop into preadipocytes; these cells will then proliferate, increasing until they get to the point where contact inhibition leads to a growth arrest phase. The number of pre-adipocytes in adipose tissue is an important factor contributing to improved marbling (Rosen \& MacDougald, 2006).

Pre-adipocytes determination is an important stage in adipogenesis because pre-adipocyte fated cells are determined from mesenchymal stem cells, which are mostly developed in the growing phase of beef cattle. Meanwhile, adipocyte differentiation mostly developed in fattening stage. Beef cattle stored most excess energy as fat, in the form of triacylglycerol (TG), which was then deposited in the pre-adipocytes (Smith \& Johnson, 2016).

Manipulating nutrition to increase the number of pre-adipocytes will improve intramuscular fat deposition. The addition of pro-differentiate hormones will trigger the arrested pre-adipocytes into re-entering the cell cycle, and undergoing two more rounds of proliferation, in a technique known as the clonal expansion phase. In this phase, it is important to identify the Zfp423 expression; this is a multi-zinc finger transcriptional protein, which signals the existence of committed pre-adipocytes in a primary SVC culture (Gupta et al., 2012). In addition, the expression of Pref- 1 is also considered to identify committed pre-adipocytes; Pref- 1 is a molecular gatekeeper for adipogenesis, which acts by maintaining the culture in the pre-adipocyte state and preventing adipocyte differentiation. The addition of dexamethasone to the preadipocytes cells suppressed Pref- 1 expression and induced PPAR $\gamma$, thus initiating the early stage of differentiation (Hudak \& Sul, 2013). Many transcriptional factors are generated by the transition of pre-adipocytes into mature adipocytes, in the terminal differentiation phase (Otto \& Lane, 2005).
Zfp423 may provide a molecular target for enhanced intramuscular adipogenesis and marbling in beef cattle (Huang et al., 2012). Pref-1 activated signaling through ERK/MAPK pathways, to promote cell proliferation and inhibit adipocyte differentiation (Wang et al., 2010). Acetate promoted both proliferation and determination of pre-adipocytes in SVC isolated from rat, through STAT3 and MAPK signaling pathways. Acetate activated leptin secretion, and increased the phosphorylation of p42 and p44 isoforms, to produce pre-adipocytes cells (Machinal-Quelin et al., 2002). Wan et al. (2009) mentioned that propionate, which was converted into glucose in the liver, supported the proliferation of different kinds of cells. Glucose is an essential nutrient which is very useful for cell growth. Propionate promoted proliferation of SVC, but it did not enhance the determination of pre-adipocytes. Pre-adipocytes are fat cell precursors and is an important cell type for adipocyte development (Florido et al., 2011).

Torii et al. (1996) stated that bovine SVC, which contained various cell types, had the potential to differentiate in response to the adipogenic stimulation. In this study, the differentiation stages of SVC were also supported by the addition of insulin, dexamethasone, and isobutylmethlxanthine.

Insulin signaling pathways acted as adipocyte metabolism regulators. The use of thiazolidinedione drugs helped to manipulate the insulin receptor signaling cascade, which promoted glucose uptake. Rosiglitazone, one of thiazolidinedione drugs, was used in this experiment to enhance SVC glucose uptake, and to increase insulin sensitivity in peripheral adipocytes.

Activation of acetate to acetyl-CoA promoted the accumulation of lipid or triglyceride deposition in the adipose tissue. In ruminants, acetate carbons come into play twice, once as the source of acetyl-CoA, to enter the malonyl-CoA pathways, and once as the source of malonyl-CoA that adds the two carbons to each cycle of the fatty acid synthesis. Acetate was preferred as a substrate for fat synthesis in subcutaneous adipocyte, while it was still possible that acetate was used for fat synthesis in intramuscular adipocyte. Acetyl CoA, which activated from acetate, was used as one precursor in fatty acid synthesis (Hong et al., 2005). Rutkowski et al. (2015) concluded that acetate still promoted cells hyperplasia, even in the differentiation stages. Based on that experiment, it has been concluded here that maximal differentiation was not attained in differentiated bovine SVC because acetate was also used up supporting cell proliferation.

The primary activity of adipocytes was to store triglycerides in periods of energy excess, and to mobilize this energy during times of deprivation (Ntambi \& Young-Cheul, 2000). Consequently, the sizes of adipocytes were increased by triglyceride deposition (Rosen \& MacDougald, 2006). Propionate was converted into glucose by gluconeogenesis in the liver. This glucose could be used for ATP production, and then stored as glycogen or incorporated into triglycerides (Zivkovic et al., 2007). Furthermore, propionate was thought to have been used for lipogenesis in muscle and adipose tissue (McDonald, 2002). 
About $90 \%$ of propionate is converted into glucose in the liver. Then, the glucose is accessible in the blood. Insulin plays an important role in adipocyte metabolism regulation by stimulating the GLUT-4 expression, which in turn mediates glucose uptake in adipose tissue. Glucose was seen as an important source of ATP in the adipocytes, and was used for triglyceride synthesis (Frayn \& Humphreys, 2011). Besides that, GLUT-4 also led to adipocyte hyperplasia via enhanced fatty acid esterification (Herman et al., 2012).

\section{CONCLUSION}

Acetate is preferred to highly produce in the proliferation stage, which is the growing stage of beef cattle, because it effectively promotes pre-adipocyte determination from mesenchymal stem cells through increasing the expression of Zfp423 and Pref-1. Propionate is preferred to be highly produced in the differentiation stage, which is the fattening stage of beef cattle, because it significantly enhances pre-adipocyte differentiation into mature adipocytes through increasing lipid accumulation of adipocytes, triglycerides contents, and the expression of adipogenic-related marker. Further research on the ratio of acetate and propionate in the diet of living animals must be done to increase the validity of this experiment.

\section{CONFLICT OF INTEREST}

The authors of this article declare that they have no conflicts of interest. All the authors contributed equally to this work.

\section{REFERENCES}

Albrecht, E., T. Gotoh, F. Ebara, J. X. Xu, T. Viergutz, G. Nürnberg, S. Maak, \& J. Wegner. 2011. Cellular conditions for intramuscular fat deposition in Japanese Black and Holstein steers. Meat Sci. 89: 13-20. https://doi. org/10.1016/j.meatsci.2011.03.012

Brooks, M. A., C. W. Choi, D. K. Lunt, R. K. Miller, C. B. Choi, \& S. B. Smith. 2011. CASE STUDY: Carcass and meat characteristics and M. longissimus thoracis histology of beef from calf-fed and yearling-fed Angus steers. The Professional Animal Scientist 27: 385-393. https://doi. org/10.15232/S1080-7446(15)30503-9

dela Cruz, J. F., Y. K. Oh, \& S. G. Hwang. 2015. The control of stromal vascular cell differentiation by retinoic acid and calcium in Hanwoo beef cattle adipose tissue. J. Anim. Prod. Advance 5: 835-844. https://doi.org/10.5455/ japa.20151118020233

Fernyhough, M. E., E. Okine, G. Hausman, J. L. Vierck, \& M. V. Dodson. 2007. PPAR $\gamma$ and GLUT-4 expression as developmental regulators/markers for preadipocyte differentiation into an adipocyte. Domest. Anim. Endocrinol. 33: 367378. https://doi.org/10.1016/j.domaniend.2007.05.001

Florido, R, T. Tchkonia, \& J. L. Kirkland. 2011. Aging and adipose tissue. In Handbook of the Biology of Aging. 7th Edition. pp. 119-139.

Frayn, N. K. \& S. M. Humphreys. 2011. Metabolic characteristics of human subcutaneous abdominal adipose tissueafter overnight fast. Am. J. Physiol. Endocrinol. Metab. 302: E468-E475. https://doi.org/10.1152/ajpendo.00527.2011

Guclu, M., O. O. Gul, S. Cander, O. Unal, G. Ozkaya, E.
Sarandol, \& C. Ersoy. 2015. Effect of rosiglitazone and insulin combination therapy on inflammation parameters and adipocytokine levels in patients with type $1 \mathrm{DM}$. J. Diabetes Res. 22: 18-23. https://doi.org/10.1155/2015/807891

Gupta, R. K., Z. Arany, P. Seale, R. J. Mepani, L. Ye, H. M. Conroe, Y. A. Roby, H. Kulaga, R. R. Reed, \& B. M. Spiegelman. 2010. Transcriptional control of preadipocyte determination by Zfp423. Nature 464: 619. https://doi. org/10.1038/nature08816

Gupta, R. K., R. J. Mepani, S. Kleiner, J. C. Lo, M. J. Khandekar, P. Cohen, A. Frontini, D. C. Bhowmick, L. Ye, S. Cinti, \& B. M. Spiegelman. 2012. Zfp423 expression identifies committed preadipocytes and localizes to adipose endothelial and perivascular cells. Cell Metab. 15: 230-239. https://doi. org/10.1016/j.cmet.2012.01.010

Hausman, D. B., M. DiGirolamo, T. J. Bartness, G. J. Hausman, \& R. J. Martin. 2001. The biology of white adipocyte proliferation. Obes. Rev. 2: 239-254. https://doi. org/10.1046/j.1467-789X.2001.00042.x

Hausman, G. J., M. V. Dodson, K. Ajuwon, M. Azain, K. M. Barnes, L. L. Guan, Z. Jiang, S. P. Poulos, R. D. Sainz, S. Smith, \& M. Spurlock. 2009. Board-invited review: the biology and regulation of preadipocytes and adipocytes in meat animals. J. Anim. Sci. 87: 1218-1246. https://doi. org/10.2527/jas.2008-1427

Herman, M. A., O. D. Peroni, J. Villoria, M. R. Schön, N. A. Abumrad, M. Blüher, S. Klein, \& B. B. Kahn. 2012. A novel ChREBP isoform in adipose tissue regulates systemic glucose metabolism. Nature 484: 333. https://doi. org/10.1038/nature10986

Hong, Y. H., Y. Nishimura, D. Hishikawa, H. Tsuzuki, H. Miyahara, C. Gotoh, K. C. Choi, D. D. Feng, C. Chen, H. G. Lee, \& K. Katoh. 2005. Acetate and propionate short chain fatty acids stimulate adipogenesis via GPCR43. Endocrinology 146, no. 12: 5092-5099. https://doi. org/10.1210/en.2005-0545

Huang, Y., A. K. Das, Q. Y. Yang, M. J. Zhu, \& M. Du. 2012. Zfp423 promotes adipogenic differentiation of bovine stromal vascular cells. PloS one 7: e47496. https://doi. org/10.1371/journal.pone.0047496

Hudak, C. S. \& H. S. Sul. 2013.Pref-1, a gatekeeper of adipogenesis. Front Endocrinol. 4: 79. https://doi.org/10.3389/ fendo.2013.00079

Kras, K. M., D. B. Hausman, G. J. Hausman, \& R. J. Martin. 1999. Adipocyte development is dependent upon stem cell recruitment and proliferation of preadipocytes. Obes. Res. 7: 491-497. https://doi.org/10.1002/j.1550-8528.1999. tb00438.x

Lee, S. H., C. Gondro, J. V. D. Werf, N. K. Kim, D. J. Lim, E. W. Park, S. J. Oh, J. P. Gibson, \& J. M. Thompson. 2010. Use of a bovine genome array to identify new biological pathways for beef marbling in Hanwoo (Korean Cattle). BMC Genomics 11: 623. https://doi.org/10.1186/1471-2164-11-623

Machinal-Quelin, F., M. N. Dieudonne, M. C. Leneveu, R. Pecquery, \& Y. Giudicelli. 2002. Proadipogenic effect of leptin on rat preadipocytes in vitro: activation of MAPK and STAT3 signaling pathways. Am. J. Physiol. Cell Physiol. 282: C853-C863. https://doi.org/10.1152/ ajpcell.00331.2001

McDonald, P. 2002. Animal Nutrition. Pearson Education Publisher.

Moseti, D., A. Regassa, \& W. K. Kim. 2016. Molecular regulation of adipogenesis and potential anti-adipogenic bioactive molecules. Int. J. Mol. Sci. 17: 124. https://doi. org/10.3390/ijms17010124

Nayananjalie, W. A. D., T. R. Wiles, D. E. Gerrard, M. A. McCann, \& M. D. Hanigan. 2015. Acetate and glucose incorporation into subcutaneous, intramuscular, and visceral fat of finishing steers. J. Anim. Sci. 93: 2451-2459. https:// 
doi.org/10.2527/jas.2014-8374

Ntambi, J. M. \& K. Young-Cheul. 2000. Adipocyte differentiation and gene expression. J. Nutr. 130: 3122S-3126S. https:// doi.org/10.1093/jn/130.12.3122S

Otto, T. C. \& M. D. Lane. 2005. Adipose development: from stem cell to adipocyte. Crit. Rev. Biochem. Mol. Biol. 40: 229-242. https://doi.org/10.1080/10409230591008189

Rosen, E. D. \& O. A. MacDougald. 2006. Adipocyte differentiation from the inside out. Nat. Rev. Mol. Cell Biol. 7: 885. https://doi.org/10.1038/nrm2066

Rutkowski, J. M., J. H. Stern, \& P. E. Scherer. 2015. The cell biology of fat expansion. J. Cell Biol. 208: 501-512. https:// doi.org/10.1083/jcb.201409063

Russell, J. B. 1998. The importance of $\mathrm{pH}$ in the regulation of ruminal acetate to propionate ratio and methane production in vitro. J. Dairy Sci. 81: 3222-3230. https://doi.org/10.3168/ jds.S0022-0302(98)75886-2

Shao, M., J. Ishibashi, C. M. Kusminski, Q. A. Wang, C. Hepler, L. Vishvanath, K. A. MacPherson, S. B. Spurgin, K. Sun, W. L. Holland, \& P. Seale. 2016. Zfp423 maintains white adipocyte identity through suppression of the beige cell thermogenic gene program. Cell Metab. 23: 1167-1184. https://doi.org/10.1016/j.cmet.2016.04.023

Smith, S. B \& B. J. Johnson. 2016. Marbling: management of cattle to maximize the deposition of intramuscular adipose tissue. J. Anim. Sci. 94: 382. https://doi.org/10.2527/ jam2016-0794
Torii, S., T. Matsui, \& H. Yano. 1996. Development of intramuscular fat in Wagyu beef cattle depends on adipogenic or antiadipogenic substances present in serum. Animal Sci. J. 63: 73-78. https://doi.org/10.1017/S1357729800028307

Vishvanath, L., K. A. MacPherson, K. Hepler, Q. A. Wang, M. Shao, S. B. Spurgin, M. Y. Wang, C. M. Kusminski, T. S. Morley, \& R. K. Gupta. 2016. Pdgfr $\beta+$ mural preadipocytes contribute to adipocyte hyperplasia induced by high-fat-diet feeding and prolonged cold exposure in adult mice. Cell Metab. 23: 350-359. https://doi.org/10.1016/j. cmet.2015.10.018

Wan, R., J. P. Du, L. P. Ren, \& Q. X. Meng. 2009. Selective adipogenic effects of propionate on bovine intramuscular and subcutaneous preadipocytes. Meat Sci. 82: 372-378. https:// doi.org/10.1016/j.meatsci.2009.02.008

Wang, Y., L. Zhao, C. Smas, \& H. S. Sul. 2010. Pref-1 interacts with fibronectin to inhibit adipocyte differentiation. Mol. Cell Biol. 30: 3480-3492. https://doi.org/10.1128/ MCB.00057-10

Wattiaux, M. A. 1996. Dairy essentials reproduction and genetic selection. Birth 42, no. 32: 25.

Wheeler, T. L., L. V. Cundiff, \& R. M. Koch. 1994. Effect of marbling degree on beef palatability in Bostaurus and Bosindicus cattle. J. Anim. Sci. 72: 3145-3151. https://doi. org/10.2527/1994.72123145x

Zivkovic, A. M., J. B. German, \& A. J. Sanyal. 2007. Comparative review of diets for the metabolic syndrome: implications for nonalcoholic fatty liver disease. Am. J. Clin. Nutr. 86: 285-300. https://doi.org/10.1093/ajcn/86.2.285 